\title{
Corneal amyloidosis
}

\author{
JENNIFER WATTS AND HELENA FRANK \\ From the Royal Victoria Hospital, Poole Road, Bournemouth BH4 9DG
}

SUMMARY A 54-year-old man presented with a corneal lesion which on excision biopsy was found to be composed of amyloid. This material was presumably laid down in response to chronic irritation from the scarred lid and thus represents an example of secondary localised amyloidosis.

A 54-year-old man presented to the outpatients department complaining of a longstanding sore right eye. Thirty years previously he had sustained an injury to the right upper lid in which tissue was lost. The lid had been repaired with a skin graft and the tarsal plate sutured, but the lid had a rounded notch in the margin, with entropion, and the tarsal surface was very uneven owing to bunching and scarring of the tarsal repair. Thus over a period of some 30 years part of the right cornea had been exposed and had undergone constant trauma from the deformed lid. The discomfort had been bearable until two years previously, since when tearing and photophobia had forced him to cover the eye and eventually to seek advice.

On examination the vision was $6 / 4$ right and $6 / 6$ left. There was a raised vascularised irregular area on Correspondence to Mrs J Watts, FRCS. the left cornea close to the limbus at 2 o'clock. This extended towards the centre of the cornea for $3 \mathrm{~mm}$. This raised area corresponded with the upper lid defect.

Excision biopsy of the abnormal limbal and corneal area was performed. The defect was allowed to heal spontaneously. Histological examination showed that this tissue had a normal epithelium with nodular deposits of amyloid in the deeper layers (Figs. 1, 2). It stained red with Congo red and displayed dichroism, that is, a change in colour that varies with the plane of polarised light (Fig. 3). Amyloid is dichroic only to green light.

Later the upper lid deformity was revised with full thickness excision of the scarred section of lid to prevent further irritation of the globe. The lid tissue was sent for histological examination. This showed that the upper lid was scarred throughout its thick-
Fig. 1 Deposits of amyloid in the cornea. $(H E \times 35$.)

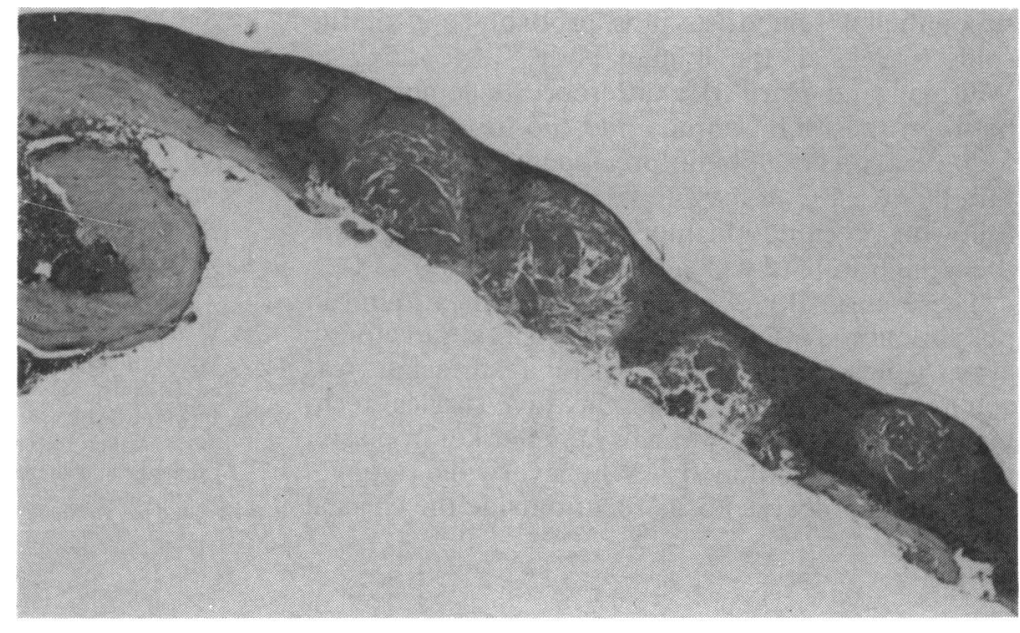




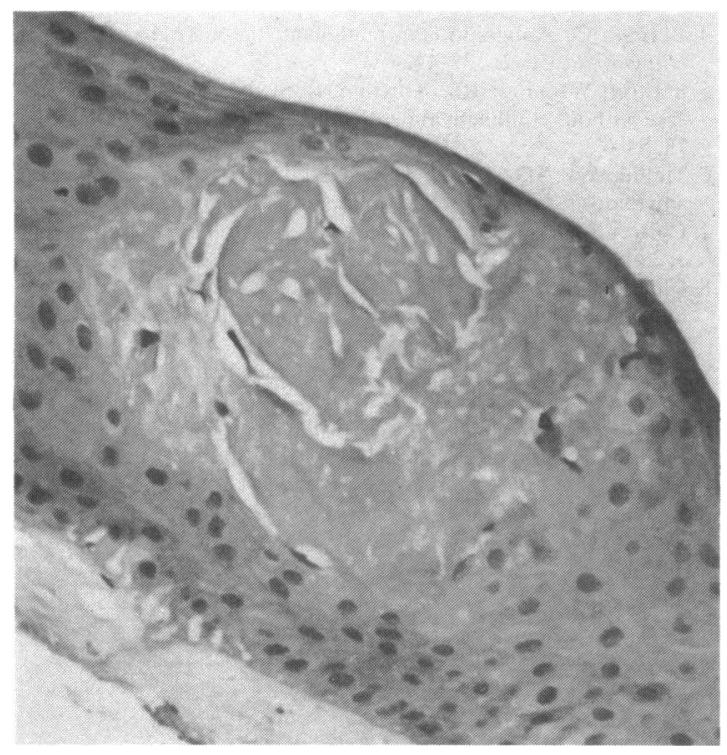

Fig. 2 Higher magnification of amyloid deposit. (HE $\times 210$.)

ness, but there was no evidence of amyloid. Nor was there evidence of amyloid deposition in any other organ of the body, and the patient was otherwise in good health.

\section{Discussion}

There are a number of conditions in which amyloid is found in the eye. Yanoff and Fine' classify amyloidosis into two main groups, primary and secondary, each of which is subdivided into systemic and local. Systemic primary amyloidosis is sometimes associated with plasmacytic and lymphocytic neoplasia; it shows a distribution of amyloid in the alimentary tract, the cardiopulmonary system, and the skin. The

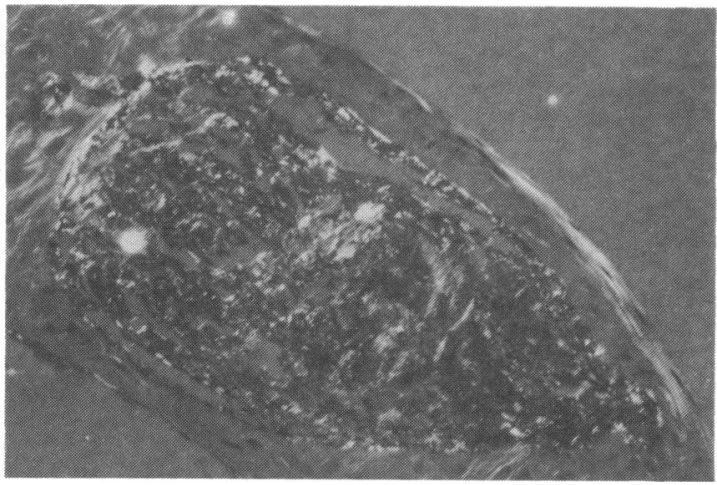

Fig. 3 Staining with Congo red showed apple green colour of amyloid deposit in polarised light. $(\times 145$.) eye may be involved in a number of ways, the most important being the appearance of vitreous opacities, but ocular palsies, neuroparalytic keratitis, and glaucoma may result from amyloid deposition in the tissues. Amyloid fibrils here consist of fragments of immunoglobulin light chains.'

Localised primary amyloidosis may also be found in the eye in the form of small red nodules in the conjunctiva and lids. The intraocular structures are not involved. Lattice corneal dystrophy, one of the inherited corneal dystrophies, is considered by some to be a form of localised primary amyloidosis of the cornea.

Secondary systemic amyloidosis accompanies some chronic diseases, with amyloid deposits chiefly in the spleen, kidney, and liver. The eyelids may rarely be involved. Secondary amyloid fibrils consist of a non-immunoglobulin-related protein, amyloid A protein. ${ }^{2}$ Secondary localised amyloidosis is a condition in which amyloid is deposited as a result of chronic local inflammation and has been described in both the conjunctiva and lids. The case we describe here is an example of secondary localised amyloidosis occurring in the corneal epithelium.

Previous cases of secondary localised amyloid deposition have been reported. Clinically unrecognisable microdeposits of amyloid have been found in association with such conditions as basal cell carcinoma, Bowen's disease, ${ }^{3}$ and conjunctival sarcoidosis. ${ }^{4}$ Microdeposits have also been seen in corneas affected with a variety of disorders such as retrolental fibroplasia, phlyctenular keratoconjunctivitis, keratoconus, and penetrating trauma. ${ }^{5-7}$ Chumbley and Peacock ${ }^{8}$ reported a case of a 25-yearold woman with bilateral trachoma who developed bilateral painless massive conjunctival swellings over two years. This tissue was found to show typical staining characteristics of amyloid and contained a heavy plasmacytic infiltration. The trachoma provided the setting in which the amyloid reaction developed.

Blodi and Appley described a 66-year-old man with a six-month history of a subconjunctival lump in the palpebral fissure. This was found to be formed of amyloid. However, in this case the patient suffered from rheumatoid arthritis, and though there was no evidence of systemic amyloidosis there was a suggestion that this was an example of secondary systemic amyloidosis rather than of secondary localised amyloidosis. In 1984 Borodic et al." described a 30year-old female who presented with blepharoptosis secondary to localised non-familial amyloidosis. Amyloid was found in the tarsus and tarsal conjunctiva. The abnormal tissue showed the apparent accumulation of proteins similar to fragments of immunoglobulin polypeptides with the amyloid 
matrix, though previously such a finding was thought to be restricted to primary systemic amyloidosis.

In summary there seems to be a wide variety of conditions in which amyloid is deposited, but it still remains rare in the ocular tissues. Our case of secondary localised amyloidosis in the cornea is unusual.

Our thanks are due to Dr D Parrish and Dr M Lesna for supplying the histological findings and photographs.

\section{References}

1 Yanoff M, Fine BS. Ocular pathology: a text and atlas. 2nd ed. Philadelphia: Harper and Row, 1982: 287-8.

2 Franklin EC Amyloidosis. Bull Rheum Dis 1976; 26: 832-7.

3 Brownstein MH, Elliott R, Helwig EB. Ophthalmologic aspects of amyloidosis. Am J Ophthalmol 1970; 69: 423-30.
4 Bernath G. Amyloidosis in malignant tumours. Acta Morphol Hungarica 1956; 2: 137-44.

5 Stafford WR, Fine BS. Amyloidosis of the cornea: report of a case without conjunctival involvement. Arch Ophthalmol 1966; 75: 53-6.

6 McPherson SD Jr, Kiffney GT Jr, Freed CC. Corneal amyloidosis Trans Am Ophthalmol Soc 1966; 64: 148-62.

7 Collyer RT. Amyloidosis of the cornea. Can J Ophthalmol 1968; 3: 35-8.

8 Chumbley LC, Peacock OS. Amyloidosis of the conjunctiva-an unusual complication of trachoma. South Afr Med J 1977; 52: 897-8.

9 Blodi FC, Apple DJ. Localised conjunctival amyloidosis. Am J Ophthalmol 1979; 88: 346-50.

10 Borodic G, Beyer-Machule C, Millin J, Conte J, Foster CS. Immunoglobulin deposition in localised conjunctival amyloidosis. Am J Ophthalmol 1984; 98: 617-22.

Accepted for publication 3 February 1989. 